RESEARCH REPORT

\title{
ASSOCIATION OF DEPRESSION, ANXIETY AND STRESS WITH QUALITY OF SLEEP AMONG DPT STUDENTS OF ZCRS
}

\begin{abstract}
AIMS AND OBJECTIVES

Sleep deprivation is a major contributor of health and mental problems that may cause serious difficulties in accomplishing ADL's among students although severe health and mental conditions have direct impact on the quality and quantity of sleep too. Thus, this study aims to determine the quality of sleep and its association between anxiety, depression, and stress to improve health related quality of life (HRQOL) among undergraduate DPT students of ZCRS.
\end{abstract}

\section{STUDY DESIGN}

A cross-sectional survey

\section{SAMPLE SELECTION}

325 students were selected through convenience sampling technique from pre-clinical (1st, 2nd) and clinical (3rd, 4th, 5th) years of DPT program.

\section{PROCEDURE}

Data was collected on by providing Pittsburgh Sleep Quality Index and Depression, Anxiety and Stress Scale-21 to both students of pre-clinical and clinical years at beginning, middle and end of semester to determine the association of related outcome measures.

\section{RESULTS}

Strong association was found between sleep deprived students with depression, anxiety, and stress on chi-square test of association $(p<0.05)$.

\section{CONCLUSION}

It was concluded that high prevalence of anxiety followed by depression and stress with the quality of sleep along with the amount of sleep in university students during all three phases of their academic semester. Although studies proposed genetic co-relation with anxiety, depression and stress as well as with the quality of sleep.

\section{KEYWORDS}

Depression, Anxiety, Sleep, sleep deprivation, Health-related quality of life, activities of daily living.

\author{
Beenish Zafar \\ Assistant Professor \\ Ziauddin College Rehabilitation \\ Sciences \\ Ziauddin University \\ beenish_zafar@yahoo.com

\section{Farzana Amir} \\ Head of Department \\ Preventive Cardiology \& Cardiac \\ Rehabilitation \\ Chair Institutional Review Committee \\ TABBA Heart Institute \\ farzana.Hashmi@tabbaheart.org

\section{Syed Wasif Ali} \\ Associate Professor \\ Jinnah College of Rehabilitation \\ Sciences \\ Swasif.1974@gmail.com
}

[Zafar B,Amir F,Ali SW. Association of Depression, Anxiety and Stress with Quality of Sleep among DPT students of ZCRS Pak. j. rehabil. 2019;8(1):37-42] 


\section{INTRODUCTION}

Sleep deprivation can cause serious health and mental problems and can cause issues in performing activities of daily living'. Sleep, a compute of quantitative and qualitative components'. The duration of sleep comes under quantitative component while the depth and feeling of relaxation upon arousing is the domain of, the qualitative component'. Sleep quality and duration generally varies among genders and ages, though findings are inconsistent across studies. As according to one study, female students or individuals with increased age has been identified as having a higher risk of poor sleep qualityl while one another study suggested one-third adult population is affected by sleep disorders ${ }^{2}$.

Sleep disturbances are so frequently perceived as a symptom that is indicative of certain psychiatric disorders as well as they are listed as diagnostic criterion under Diagnostic and Statistical Manual of Mental Disorders (DSM-IV)

A cross-sectional research performed at Auckland gave an idea about the correlation of sleep with anxiety and depression that was found to be total of $39.4 \%$ of the students had considerable sleep symptoms lasted longer than 1 month. The most prevailed reason for sleep symptoms were depression and anxiety, found to be $17.3 \%$ and $19.7 \%$ respectively 4 .

Whereas stress is mind's and body's way of dealing with new complexity or complication in life, it's good for making competitive and motivated individuals or sometimes this stress produces negative impact that leads to anxiety and depression ${ }^{5}$. People with family history of depression and anxiety are at higher risk of sleep disorders 6 .

Lack of involvement, loss of interest, persistent feeling of sadness, aversion to activity and low mood all leads to depression?; Depression is not just low spirits or bad mood that can influence a person's opinion, belief and behavior, judgment, tendencies, feelings, and sense of frame of comfort and well-being. It's a grave intellectual health state (mental illness) influencing both psychological and physical health ${ }^{6-7}$.

However, Anxiety is communal term for quite a few disorders such as fear, panic, alarm, dread, terror, apprehension, nervousness, and worrying etc. Hence affects our behavior ${ }^{7}$. Occasional anxiety is a normal part of life ${ }^{7}$. One may feel anxious when faced with a difficulty at work, prior taking a test, or making an important decision. Anxiety is simply considered as state of uneasiness in usual day to day life $e^{6-7}$.

One study revealed the prevalence of anxiety among medical students attending universities as 43.7\% in Pakistan, $54.5 \%$ in Malaysia, $65.5 \%$ in Greece, and $69 \%$ in Beirut, while the prevalence of anxiety among students attending private medical colleges has been estimated to be $29.4 \%$ in Israel, $56 \%$ in India, and $60 \%$ in Pakistan ${ }^{8}$. However students with poor mental health suffering from depression, anxiety and stress are subjected to various problems including, bad academic, abandoning studies (drop out), and difficulty in managing relation with friends and family, and incompetent to survive a stressful situation. It results in reduced self-trust that had a direct impact on students' academic performance 6 -8

The Pittsburgh Sleep Quality Index (PSQI), used to assess the sleep quality during the past month. It has been designed in such a way that it can be used in multiple settings, including research and clinical activities, for the identification of sleep disorders. It has 9 questions and 7 components that evaluated participant's sleep quality, sleep latency, sleep duration, habitual sleep efficiency, sleep disturbances, uses of sleep medication and daytime dysfunction over the past month. This tool covered 19 individual items. Each item was scored on 0-3 interval scale, yielding one global score on the whole ranging from 0 to 21 . Individuals that attained higher than 5 are considered sleep deprived ${ }^{9-10}$.

The Depression, Anxiety and Stress Scale (DASS-21) assessed participants' mental health during the past week. It is a dimensional rather than a categorical conception of psychological order. This self-administrated questionnaire has 21 items related to three components indicating mental health that are stress, anxiety and depression; each module consisted of 7 questions. Participants ranked each question from 0 to 3, 0 indicating the item "don't apply to them at all", to 3 indicating that the item "apply to them very much". Subjects were given 4-point severity scales to rate the degree, they had been through each condition on the period of last week ${ }^{10}$.

\section{METHODOLOGY}

\section{Study Design}

Longitudinal Study

\section{Sample Size}

A sample of 325 students was recruited in the study.

\section{Study Setting and Participants}

This longitudinal study was conducted among the DPT students fromlst, 2nd, 3rd, 4th and 5th year at Ziauddin College of Rehabilitation Sciences.

\section{Study Duration}

This survey was conducted over the six months period.

\section{Sampling Technique}

Students were recruited for this survey through convenience sampling technique. 


\section{Inclusion and Exclusion Criteria}

- DPT students from 1st, 2nd, 3rd, 4th and 5th year aged 18-25 years with written consent to participate in this survey were included.

- Any other medical and paramedical students or participants who have submitted incomplete questionnaires were also excluded $3,11,12$

\section{Data Collection Tools}

The participants were given a set of questionnaires consisted a consent form, a sociodemographic questionnaire that required each student to provide their age, gender and year of study and a DASS scoring system (the Depression, Anxiety and Stress Scale) ${ }^{10}$ along with the Pittsburgh Quality of Sleep Index (PSQI) ${ }^{9-10}$. Both the tools had open access to be used as per required. The questionnaire was culture free and that made the test feasible to adapt to any culture ${ }^{11}$.

\section{Data Collection Procedure}

Data was obtained through questionnaires among participants. Prior to the study signed consent was obtained from all the participants and were informed about the objectives and goals of this survey and assured anonymity. The recruitment was done at the start of the research that is students of all DPT years at the beginning of semester and collection of data was performed in three phases:

(1) Start of the semester: the data was collected from all years students enrolled in undergraduate DPT program.

(2) Middle of the semester: then again students were given the same questionnaires to be evaluated during mid-semester.

(3) At the end of the semester: students yet again were assessed by the same questionnaires at the closing stages of the semester a week before the finals.

\section{Data Analysis Strategies}

SPSS version-20 was used for data analysis. Participants demographic details were represented through mean age and percentage whereas scoring on PSQI and DASS-I were shown in terms of frequency and percentages.

\section{Ethical Considerations}

Both the tools had open access therefore no permission was required to utilize these questionnaires as they had open right to use. Prior to consent, detailed understanding of questionnaires was provided to the participants.

\section{RESULTS}

308 out of 325 questionnaires received were correctly filled by the enrolled participants with mean age of $20 \pm 1.5$ where $20.1 \%$ were male and $79.9 \%$ were female students.

Results obtained at the start of semester from PSQI concluded that $76.0 \%$ students were deprived of sleep. Whereas depression, anxiety and stress calculated on DASS-21 scale showed that $14 \%$ students were mild depressive, $22.4 \%$ were moderately depressed, $10.1 \%$ were severe while only $10.4 \%$ showed extremely severe depression. Similarly anxiety was found to be normal in $26.9 \%, 9.4 \%$ were mild anxious while $10.7 \%$ were in severe anxiety. Moreover, stress was reported normal in $57.1 \%$ of students, moderate in $15.6 \%$ of students, severe in $9.7 \%$ students and extremely severe in $12.7 \%$ of students.

Another set of data was collected at the mid of the semester that showed $73.2 \%$ students had reduced sleep quality calculated in PSQI. Furthermore, on DASS-21, $12.6 \%$ exhibited mild symptoms of depression, $18 \%$ had moderate depression, while $11.4 \%$ were with severe depression. Anxiety was found to be normal in $35.6 \%$, mild in $10.1 \%$, moderate in $16.4 \%$, severe in $15.5 \%$ students. On the contrary stress was reported normal in $53.6 \%$, mild in $13.6 \%$, moderate in $14.5 \%$, severe in $12.3 \%$, and extremely severe in $6.0 \%$ students.

The last data was gathered at the end of the semester. Sleep quality measured on PSQI revealed that, $72.2 \%$ students had poor sleep characteristics. Estimation on DASS-21for depression was ranked normal in $39.1 \%$, mild in $13.1 \%$, moderate in $19.0 \%$, severe in $16.5 \%$ students. While anxiety appeared tobe normal in $22.9 \%$, mild in $7.3 \%$, moderate in $26.0 \%$, severe in $13.8 \%$ students. Although stress was found to be normal in $48.3 \%$, mild in $14.1 \%$, moderate in $16.5 \%$, severe in $13.5 \%$ students. The prevalence of Depression, Anxiety and Stress scores of all phases of semester are depicted in Table-1.

A chi-square test of association showed significant association $(p<0.05)$ of sleep with depression, anxiety and stress in all phases of semester as shown in Figure 1, 2 and 3.

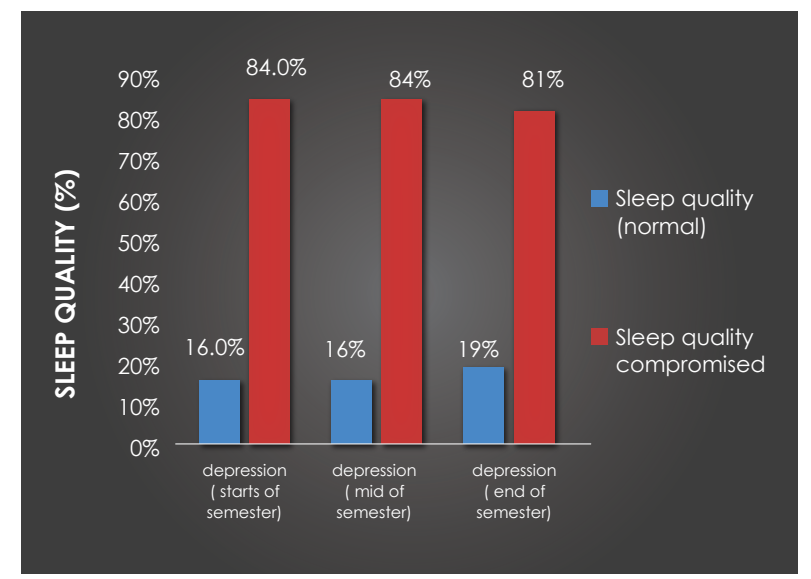

Figure 1. Association of depression with sleep 


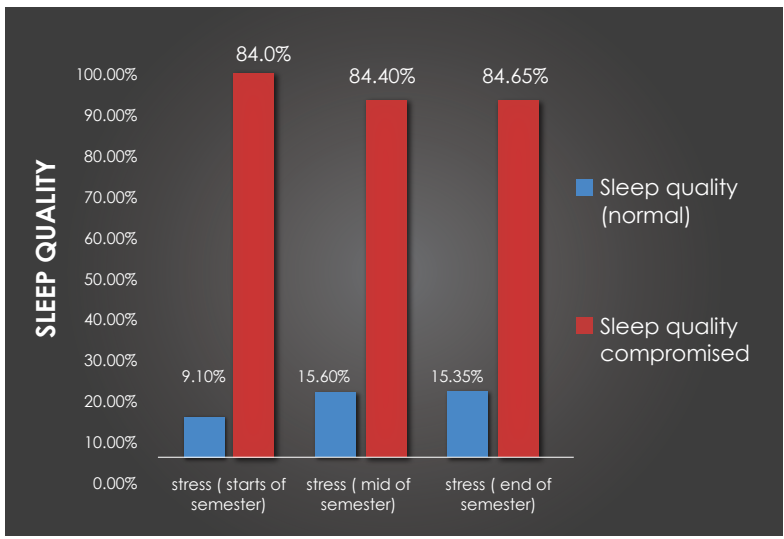

Figure 2. Association of stress with sleep

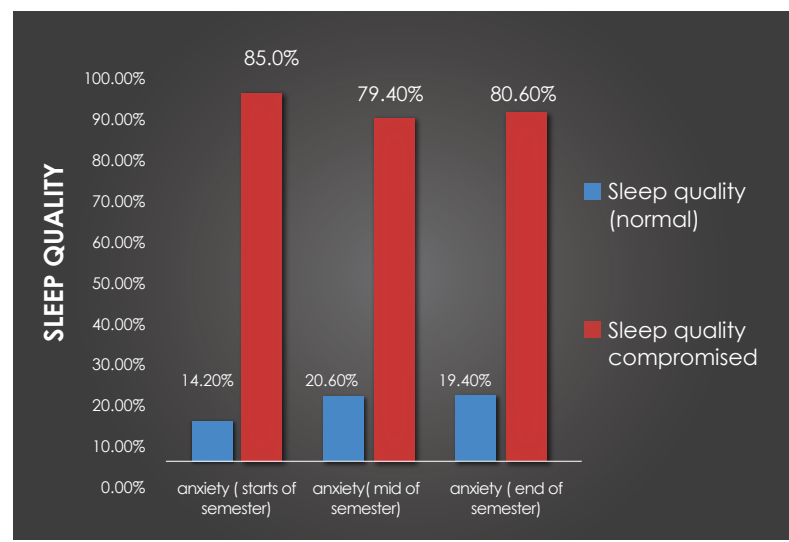

Figure 3. Association of anxiety with sleep

Table 1. Prevalence of depression, anxiety, and stress at the start, mid and the end of Semester

\begin{tabular}{|c|c|c|c|c|c|}
\hline & \multirow[t]{2}{*}{ Tool } & \multirow[t]{2}{*}{ Category } & $\begin{array}{l}\text { Frequency. } \\
\text { percentage }\end{array}$ & $\begin{array}{l}\text { Frequency: } \\
\text { percentage }\end{array}$ & $\begin{array}{l}\text { Frequency, } \\
\text { percentage }\end{array}$ \\
\hline & & & $\begin{array}{l}\text { (Stan of } \\
\text { semester) }\end{array}$ & $\begin{array}{l}\text { (Mad of } \\
\text { semester) }\end{array}$ & $\begin{array}{l}\text { (End of } \\
\text { semester) }\end{array}$ \\
\hline \multirow[t]{5}{*}{1} & \multirow[t]{5}{*}{ DASS (depression) } & Normal & $43.2 \%$ & $45.7 \%$ & $49.1 \%$ \\
\hline & & Mild & $14 \%$ & $12.6 \%$ & $13.1 \%$ \\
\hline & & Moderate & $22.4 \%$ & $18 \%$ & $19.0 \%$ \\
\hline & & Severe & $10.1 \%$ & $11.4 \%$ & $16.5 \%$ \\
\hline & & $\begin{array}{l}\text { Extremely } \\
\text { severe }\end{array}$ & $10.4 \%$ & $12.3 \%$ & $12.2 \%$ \\
\hline \multirow[t]{5}{*}{2} & \multirow[t]{5}{*}{ DASS (anxiety) } & Normal & $26,9 \%$ & $35.6 \%$ & $22.9 \%$ \\
\hline & & Mild & $9.4 \%$ & $10.1 \%$ & $7.3 \%$ \\
\hline & & Moderate & $26 \%$ & $16.4 \%$ & $26.0 \%$ \\
\hline & & Severe & $10 . \%$ & $15.5 \%$ & $13.8 \%$ \\
\hline & & $\begin{array}{l}\text { Extremely } \\
\text { severe }\end{array}$ & $26.9 . \%$ & $22.4 \%$ & $30.0 \%$ \\
\hline \multirow[t]{5}{*}{3} & \multirow[t]{5}{*}{ DASS (stress) } & Normal & $57.1 \%$ & $53.6 \%$ & $48.3 \%$ \\
\hline & & Mild & $12.7 \%$ & $13.6 \%$ & $14.1 \%$ \\
\hline & & Moderate & $15.6 \%$ & $14.5 \%$ & $16.5 \%$ \\
\hline & & Severe & $9.7 . \%$ & $12.3 \%$ & $13.5 \%$ \\
\hline & & $\begin{array}{l}\text { Extremely } \\
\text { severe }\end{array}$ & $4.9 . \%$ & $6.0 \%$ & $7.6 . \%$ \\
\hline
\end{tabular}




\section{DISCUSSION}

The prevalence of poor sleep quality in the present longitudinal study was $73.66 \%$. Whereas different studies stated different prevalence for sleep disorders, in Wuhan University, had $17.7 \%$ of students had poor sleep ${ }^{13}$ while $55.8 \%$ had been reported sleep deprived in Ethiopia $^{10}$. Moreover, $72 \%$ of students suffer from poor sleep in north border university Saudi Arabial4. However, another study conducted on university students in Lebanon reported $50.8 \%$ of students had poor sleep quality ${ }^{6}$ while students of Klaipeda reported $69.9 \%{ }^{15}$, in Lahore $77.2 \%$ were suffered from sleeplessness ${ }^{16}$. Hence, a study stated that poor-quality sleep leads to depression, and anxiety ${ }^{14}$ and bad behaviors ${ }^{3}$ that are due to academic pressure. Also, private university students are more under pressure than the others it could be due to high fees ${ }^{8}$.

As depression is common among students reported in the existing study $57.3 \%$, other studies conducted in several universities report depression among their students as $10.6 \%$ had been reported in Wuhan University ${ }^{13}$ and $50.8 \%$ in Ethiopian students 10 . Whereas the study conducted on high school students, Chinese adolescent in Guandong stated $6.4 \%$ of students who showed depressive symptoms ${ }^{17}$. The undergraduate students of Sindh, Pakistan reported $48 \%$ students with depression ${ }^{11}$ while study occurred in Islamabad reported $40.9 \%^{18}$. A survey conducted in several universities in Auckland reported $17.3 \%{ }^{4}$. Anxiety reported in the current study was $72 \%$. Whereas, Anxiety observed in students of Ethiopia is $58 \%{ }^{10}$ also at north border of Saudi Arabia it was observed in $92 \%$ of medical students ${ }^{14}$ and among undergraduate students of Sindh reported was $68.4 \%^{11}$ on other hand in Islamabad $74.2 \%$ students were observed to be anxious 18 The University of Auckland stated anxiety in $19.7 \%$ of its students ${ }^{4}$. Anxiety has been reported most in transfer students, upperclassmen and those living off-campus?.

Findings from the present study indicate that there was a strong association between poor sleep quality and mental health problems i.e. depression, anxiety and stress throughout the semester. The findings obtained from one cross-sectional study conducted on female medical students stated that there was a strong association between undesirable sleep quality and depression, anxiety, and stress that can be attributed to the P-value that was equal to 0.000 . Specifically, $93.4 \%$ of students were found with compromised sleep along with depressive symptoms, while $84.1 \%$ students showed poor sleep quality with anxiety and $90.1 \%$ of students experienced undesirable sleep with stressful symptoms ${ }^{19}$. This strong association supports the findings of the present study with a P-value of 0.000 for all the variables. But the difference in percentages was found in the present study that was $83 \%$ of students with compromised sleep had depression, $86.35 \%$ of students with poor sleep quality had anxiety and $81.93 \%$ of students with low quality of sleep had stressful symptoms. Despite the fact, this difference can be attributed to gender difference as females were found with more compromised sleep along with depression, anxiety, and stress ${ }^{20}$. Another study conducted on medical students of Tehran University, Iran also showed a strong association ${ }^{21}$. However, many factors influence these variables like academic stress of mainly getting poor grades, large content of study material, exam and time constraints, insufficient family time, emotional distress, financial issues. Moreover, mental health can badly influence academic performance and may have played a role in substance abuse like smoking, caffeine consumption, etc ${ }^{22}$.The results obtained from the present study demonstrated that the mean sleep quality of male and female students had no significant difference that was consistent with the finding of multiple studies ${ }^{21-25}$. Whereas, the study done in Iran exhibited that the mean sleep quality of males were less compromised then females ${ }^{20}$.

The current study demonstrated that the mean depression, anxiety, and stress were more in females than males that were consistent with the finding of another study held at Fasa medical University ${ }^{20}$ and also in another study carried out in Islamabad showed the same results ${ }^{18}$. However, women are more often affected by depression ${ }^{4}$ whereas men are more anxious ${ }^{3-8}$. Although, the outcome of the studies varied with the results of this current study that showed stress, depression and anxiety and sleep disturbances were equal in both the genders ${ }^{13-16}$. It could be due to cultural differences. However, research stated that students who are sleep deprived had a higher incidence of depression and anxiety ${ }^{15}$. Another study reported that sleep disorder is increasing globally in adolescents aged between 13 to 16 years $^{6}$. While in another research 20 -year-old students had compromised sleep ${ }^{6-15}$.

\section{CONCLUSION}

It was concluded that high prevalence of anxiety was observed among DPT students followed by depression and stress in all three different phases. Whereas, the vast majority of students appeared to be sleep deprived. Moreover, strong associations were found between the poor quality of sleep in students who are exposed to depressive, anxiety and stress symptoms.

\section{REFERENCES}

[1] Lemma S, Gelaye B, Berhane Y, Worku A, Williams MA. Sleep quality and its psychological correlates among university students in Ethiopia: a cross-sectional study. BMC psychiatry. $2012 ; 12(1): 237$.

[2] Dikmen PY, Yavuz BG, Aydinlar El. The relationships between migraine, depression, anxiety, stress, and sleep disturbances. Acta Neurologica Belgica. 2015;115(2):117-22. 
[3] Pensuksan WC, Lertmaharit S, Lohsoonthorn V, Rattananupong T, Sonkprasert T, Gelaye B, Williams MA. Relationship between poor sleep quality and psychological problems among undergraduate students in the Southern Thailand. Walailak journal of science and technology. 2016;13(4):235.

[4] Samaranayake CB, Arroll B, Fernando AT. Sleep disorders, depression, anxiety and satisfaction with life among young adults: a survey of university students in Auckland, New Zealand. NZ Med J. 2014;127(1399):13-22.

[5] Jahan F, Siddiqui MA, Mitwally M, Zubidi A, Jasim NS, Zubidi A, Jasim HS. Perception of stress, anxiety, depression and coping strategies among medical students at Oman medical college. World Family Medicine Journal: Incorporating the Middle East Journal of Family Medicine. 2016:99(3719):1-8.

[6] Choueiry N, Salamoun T, Jabbour H, El Osta N, Hajj A, Khabbaz LR. Insomnia and relationship with anxiety in university students: a cross-sectional designed study. PloS one. 2016;1 1 (2):e0149643.

[7] Beiter R, Nash R, McCrady M, Rhoades D, Linscomb M, Clarahan M, Sammut S. The prevalence and correlates of depression, anxiety, and stress in a sample of college students. Journal of affective disorders. 2015;173:90-6.

[8] Saravanan C, Wilks R. Medical students' experience of and reaction to stress: the role of depression and anxiety. The Scientific World Journal. 2014;2014.

[9] Hershner SD, Chervin RD. Causes and consequences of sleepiness among college students. Nature and science of sleep. 2014;6:73.

[10] Lemma S, Gelaye B, Berhane Y, Worku A, Williams MA. Sleep quality and its psychological correlates among university students in Ethiopia: a cross-sectional study. BMC psychiatry. 2012;12(1):237.

[1 1] Syed A, Ali SS, Khan M. Frequency of depression, anxiety and stress among the undergraduate physiotherapy students. Pakistan journal of medical sciences. 2018;34(2):468.

[12] Al-Maddah EM, Al-Dabal BK, Khalil MS. Prevalence of sleep deprivation and relation with depressive symptoms among medical residents in King Fahd University Hospital, Saudi Arabia. Sultan Qaboos University Medical Journal. 2015;15(1):e78.

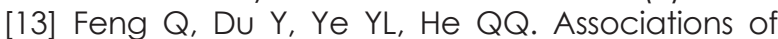
physical activity, screen time with depression, anxiety and sleep quality among Chinese college freshmen. Plos one. $2014 ; 9(6)$ :e100914.

[14] Shathele SM, Oommen A. Factors influencing the academic performance of the female medical students in preclinical and clinical years. Journal of Medicine and Medical Sciences. 2015;6(6):109-14.

[15] Jurgita A, Šarūnè B, Asta M, Akvilè V. Relations among poor sleep, anxiety and depression among the students of health sciences. Applied research in health and social sciences: interface and interaction. 2017;14(1):26-38.

[16] Waqas A, Khan S, Sharif W, Khalid U, Ali A. Association of academic stress with sleeping difficulties in medical students of a Pakistani medical school: a cross sectional survey. PeerJ. 2015;3:e840.

[17] Guo L, Deng J, He Y, Deng X, Huang J, Huang G, Gao X, Lu C. Prevalence and correlates of sleep disturbance and depressive symptoms among Chinese adolescents: a cross-sectional survey study. BMJ open. 2014;4(7):e005517.

[18] Rizvi F, Qureshi A, Rajput AM, Afzal M. Prevalence of depression, anxiety and stress (by DASS scoring system) among medical students in Islamabad, Pakistan. Br J Med Med Res. 2015;8(1):69-75.

[19] Farzaneh F, Momayyezi M, Lotfi MH. Relationship between quality of sleep and mental health in female students of Shahid Sadoughi University of Medical Sciences (2015). Journal of Fundamentals of Mental Health. 2018;20(2):167-71.

[20] Najafi Kalyani M, Jamshidi N, Salami J, Pourjam E. Investigation of the relationship between psychological variables and sleep quality in students of medical sciences. Depression research and treatment. 2017;2017.

[21] Rezaei M, Khormali M, Akbarpour S, Sadeghniiat-Hagighi K, Shamsipour M. Sleep quality and its association with psychological distress and sleep hygiene: a cross-sectional study among pre-clinical medical students. Sleep Science. 2018;1 1 (4):274.

[22] labal S, Gupta S, Venkatarao E. Stress, anxiety \& depression among medical undergraduate students \& their socio-demographic correlates. The Indian journal of medical research. 2015;141 (3):354.

[23] João KA, de Jesus SN, Carmo C, Pinto P. The impact of sleep quality on the mental health of a non-clinical population. Sleep medicine. 2018;46:69-73.

[24] Isaac F, Greenwood KM. The relationship between insomnia and depressive symptoms: genuine or artifact? Neuropsychiatric disease and treatment. $2011 ; 7: 57$

[25] McGillivray CJ, Pidgeon AM. Resilience attributes among university students: a comparative study of psychological distress, sleep disturbances and mindfulness. European Scientific Journal. $2015 ; 11(5): 33-48$. 